\title{
CENTROS DE INOVAÇÃO E EMPREENDEDORISMO: ESTUDO BIBLIOMÉTRICO E REVISÃO SISTEMÁTICA
}

\author{
Lucas Coelho de Avila ${ }^{1 *}$ \& Romeu e Silva Neto ${ }^{2}$
}

\begin{abstract}
RESUMO
AVILA, L.C.; NETO, R.S. Centros de inovação e empreendedorismo: estudo bibliométrico e revisão sistemática. Perspectivas Online: Exatas \& Engenharia, v.10, n.27, p.54- 69, 2020.

O mundo moderno é marcado por rápidas e crescentes transformações tecnológicas, econômicas e sociais, de modo que o empreendedorismo e a inovação desempenham uma grande relevância neste contexto. Todavia, como o ambiente é caracterizado por muitas incertezas e dinamismos, é necessário que existam instituições orientadas a fornecer o apoio e o suporte de que novos negócios necessitam em seus estágios iniciais, como por exemplo, os Centros de Inovação, Parques Tecnológicos ou incubadoras de empresas. Sendo assim, o presente trabalho apresenta o objetivo de avaliar como a produção científica brasileira vem abordando a relação entre o estabelecimento de Centros de Inovação, ou outros ambientes orientados ao mesmo fim, no tocante ao desenvolvimento de empreendedorismo e inovação. Para tal, primeiramente foi realizado um estudo bibliométrico a partir do qual foi possível

a publicações relacionadas a essa temática, em comparação com os demais países do mundo. Além disso, foram destacados os periódicos responsáveis pela maior quantidade de trabalhos nacionais $\mathrm{e}$ internacionais, as principais afiliações brasileiras $\mathrm{e}$ as tendências de evolução dessas pesquisas no Brasil. Verificou-se que o Brasil ocupa o quarto lugar dentre os países, tendo trinta e dois trabalhos publicados sobre o assunto. Após isso, foi proposto um método para classificar e selecionar os trabalhos brasileiros encontrados, com base nas informações coletadas no levantamento bibliométrico, e depois foi realizada uma revisão sistemática dos artigos selecionados. Por fim, foi possível concluir que o trabalho contribui com informações relevantes para orientar novos pesquisadores a respeito de como se encontra essa temática no meio acadêmico, em especial nas pesquisas brasileiras.
\end{abstract} analisar o comportamento do Brasil quanto

Palavras-chave: Centros de Inovação; Empreendedorismo; Estudo Bibliométrico; Revisão Sistemática.

Persp. Online: exatas \& eng., Campos dos Goytacazes, 27 (10) 54 - 69 - 2020

seer.perspectivasonline.com.br 


\begin{abstract}
The modern world is characterized by fast and growing technological, economic and social transformations, so entrepreneurship and innovation presents a major role in this context. However, as the environment is marked by great uncertainty and dynamism, there is a need for institutions to provide the support that new business need in their early stages, such as Innovation Centers, Technological Parks and business incubators. Thus, this paper presents the objective of evaluating how the Brazilian scientific production has approached the relationship between the establishment of Innovation Centers, or other environments oriented towards the same end, regarding the development of entrepreneurship and innovation. To this end, a bibliometric study was first performed where it was possible to analyze the behavior of Brazil regarding

publications related to this theme, in comparison with other countries in the world; In addition, the journals responsible for the largest amount of national and international works, the main Brazilian affiliations and the evolutionary trends of these researches in Brazil were highlighted. It was found that Brazil ranks fourth among countries with twenty published papers. After that, it was proposed a method to classify and select the Brazilian papers found, based on the information collected in the bibliometric survey, and then a systematic review of the selected articles was performed. Finally, it was possible to conclude that the work contributes with relevant information to guide new researchers about how this theme is found in the academic environment, especially in Brazilian research.
\end{abstract}

Keywords: Innovation Centers; Entrepreneurship; Bibliometric study; Systematic review.

\footnotetext{
${ }^{1}$ Mestrando em Sistemas Aplicados à Engenharia e Gestão pelo Instituto Federal Fluminense - IFFluminense/Campos dos Goytacazes.

${ }^{2}$ Doutor em Engenharia de Produção pela Pontifícia Universidade Católica do Rio de Janeiro, Brasil (2002). Professor titutlar do Instituto Federal Fluminense - IFFluminense/Campos dos Goytacazes.

(*) e-mail: lcoelho_avila@hotmail.com.

Data de recebimento: 01/08/2019 Aceito para publicação: 18/02/2019.
}

Persp. Online: exatas \& eng., Campos dos Goytacazes, 27 (10) 54 - 69 - 2020

seer.perspectivasonline.com.br 


\section{INTRODUÇÃO}

O desenvolvimento e o progresso apresentam forte relação com a inovação e competitividade de produtos e serviços e a capacidade de gerenciar organizações de modo empreendedor. Sendo assim, pode-se afirmar que a mentalidade empreendedora e a capacidade de inovar desempenham um papel de grande relevância no tocante ao desenvolvimento e progresso de uma nação (LUZ et al., 2012).

Por essa razão, muitos países economicamente desenvolvidos vêm disseminando essa cultura de empreendedorismo e inovação com base em interações entre universidades, empresas e governos, que podem ser considerados como sendo importantes agentes de inovação (MACHADO et al., 2016).

Diante disso, vem sendo realizados vários esforços em prol da criação de locais que promovam ambientes propícios ao desenvolvimento do empreendedorismo e inovação. Esses locais fornecem uma infraestrutura de apoio técnico, logístico, e administrativo na tentativa de colaborar com o fortalecimento de novas ideias, projetos e empreendimentos inovadores (GUY, 1996).

Parques Científicos e Tecnológicos são locais que reúnem diversas instituições interessadas na transferência e comercialização de infraestrutura de tecnologia, apresentando foco no desenvolvimento de pesquisa e inovação (LOBJEKO; SOSNOWSKA, 2015).

A Unesco (2017) conceitua o termo "parque científico e tecnológico" como sendo qualquer tipo de cluster de alta tecnologia que busca estimular o desenvolvimento econômico regional e nacional por meio do desenvolvimento do empreendedorismo e da inovação. Como exemplo, pode-se citar os Centros de Inovação (LINK; YEONG YANG, 2018).

As incubadoras de empresas também são importantes organizações que estimulam o empreendedorismo e nutrem ideias para transformar novas empresas em empreendimentos viáveis e inovadores, impulsionando o crescimento econômico (DIAMANTOPOULOU et al., 2018).

Tendo em vista a importância e destaque que o tema vem ganhando no momento atual, o presente trabalho apresenta o objetivo de analisar as pesquisas brasileiras que abordam sobre empreendedorismo e inovação, e a criação de estabelecimentos que visam estimular e apoiar sua prática, como por exemplo, os Centros de Inovação, Parques Científicos e Tecnológicos, ou incubadoras de empresas. O objetivo é avaliar a situação do Brasil no tocante à realização dessas pesquisas, em comparação com os demais países do mundo, bem como destacar quais as principais contribuições que as pesquisas brasileiras vem oferencedo para a temática. Para tal, foi realizada uma pesquisa dividida em duas partes: primeiro, realizado um estudo bibliométrico utilizando-se a base de dados Scopus, onde foi analisada a participação brasileira com relação ao tema em comparação com os demais países do mundo, tendo sido destacados também os principais periódicos e as principais afiliações brasileiras relacionadas ao tema; logo após foram selecionados os principais trabalhos brasileiros tendo como base as informações obtidas no estudo bibliométrico, e então foi realizada uma revisão sistemática desses trabalhos.

Persp. Online: exatas \& eng., Campos dos Goytacazes, 27 (10) 54 - 69 - 2020 seer.perspectivasonline.com.br 


\section{METODOLOGIA}

A metodologia para realização desse trabalho consiste na realização de uma revisão sistemática dos principais trabalhos brasileiros que abordam o tema: "o papel dos Centros de Inovação no contexto do desenvolvimento de empreendedorismo e inovação". A escolha pela utilização da base Scopus justifica-se pelo fato desta ser considerada hoje como uma das maiores bases de dados multidisciplinar, que contém milhares de trabalhos científicos entre artigos, conferências, periódicos, entre outros; além de oferecer ferramentas inteligentes que possibilitam visualizar e analisar a pesquisa realizada (REDONDO et al., 2017). Os procedimentos para realização do trabalho foram executados da seguinte maneira:

Etapa 1 - Definição da amostra de pesquisa: a amostra pesquisada corresponde aos artigos indexados na base de dados Scopus. Não foram estabelecidas restrições temporais ou quanto aos tipos de publicações, justamente para que não fossem descartados trabalhos importantes e para que fosse possível analisar de maneira mais precisa as tendências de evolução. Sendo assim, os resultados incluem todos os trabalhos realizados sobre o tema e presentes na base até dezembro de 2019.

Etapa 2 - Definição das palavras-chave e tesauros: para que fossem encontrados trabalhos relacionados ao assunto foram definidas como palavras-chave: "innovation centers" (que significa Centros de Inovação) e "entrepreneurism" (que significa empreendedorismo). Foram definidos como tesauros de "innovation centers": "tech park", "science technological park" e "business incubator", visto que esses tesauros representam conceitos próximos ao dos Centros de Inovação. Para a palavra "enterpreneurism" foram definidos os tesauros: "enterprise", "entrepreneurship" e "entrepreneurialism" que podem ser entendidos como sinônimos da palavra-chave. A Tabela 1 apresenta as palavras-chave e tesauros utilizados.

Tabela 1: Termos utilizados na pesquisa

\begin{tabular}{|c|c|c|}
\hline & A & B \\
\hline Conceito & Centros de Inovação & Empreendedorismo \\
\hline Palavra-chave & "Innovation Center*" & "Entrepreneurism" \\
\hline Tesauros & $\begin{array}{c}\text { "tech park" } \\
\text { "science technological park" } \\
\text { "business incubator" }\end{array}$ & $\begin{array}{c}\text { "entrepreneurship" } \\
\text { "entrepreneurealism" }\end{array}$ \\
\hline
\end{tabular}

Etapa 3 - Exploração dos resultados: após realizada a busca na base com as palavraschave e tesauros definidos, foi possível encontrar o número total de trabalhos que se relacionam ao tema. Os resultados foram analisados mediante um diagrama de Venn, no qual foram apresentados os resultados referentes ao termo A (Centros de Inovação), B (Empreendedorismo) e A/B (os trabalhos que se relacionam concomitantemente aos temas Centros de Inovação e empreendedorismo), que são os que de fato representam o objeto deste estudo. Com relação aos resultados para a interseção $\mathrm{A} / \mathrm{B}$, foram identificados os principais periódicos, e os principais países responsáveis pela maior quantidade de publicações sobre o tema.

Etapa 4 - Análise da participação brasileira nas pesquisas: por meio da bibliometria, é possível levantar informações a respeito das contribuições brasileiras para a temática

Persp. Online: exatas \& eng., Campos dos Goytacazes, 27 (10) 54 - 69 - 2020

seer.perspectivasonline.com.br 
abordada. Após identificados e ilustrados o total de trabalhos relacionados ao tema em um diagrama de Venn, foram destacados aqueles que apresentam a participação de alguma instituição brasileira para sua realização. Sendo assim, foi elaborado outro diagrama de Venn, porém desta vez considerando-se somente os trabalhos brasileiros, para que fosse possível analisar como se comportou o Brasil no tocante a essas pesquisas, em comparação com os outros países do mundo de uma forma geral. Foram destacadas as principais afiliações brasileiras e foi realizada uma análise cronológica a respeito das tendências de evolução das pesquisas brasileiras.

Etapa 5 - Classificação dos trabalhos brasileiros: para que fosse possível classificar os trabalhos de acordo com sua relevância, cada um foi pontuado de acordo com os seguintes critérios: número de citações (NC), ano de publicação (AP), principais afiliações (PA) e principais periódicos (PP). Para tal, foi proposto um método que engloba os critérios mencionados de acordo com as preferências e grau de importância atribuídos pelo pesquisador. A pontuação foi atribuída da seguinte maneira para cada critério:

- Número de citações: considerou-se este como sendo o principal critério para se determinar a relevância dos trabalhos. Sendo assim, sua pontuação foi determinada por meio da multiplicação do número de citações por 10.

- Ano de publicação: a pontuação para esse critério é definida de acordo com a seguinte fórmula: (ano de publicação - 2003) * 3. Dessa forma, a pontuação pode variar entre 0 e 48 , priorizando os trabalhos mais atuais. Foi utilizado o ano de 2003 na fórmula pelo fato de que o primeiro trabalho publicado sobre o tema no Brasil data desse ano. Sendo assim, o trabalho mais antigo não pontua nesse critério, e no decorrer dos anos as pontuações foram aumentando gradativamente até chegar aos trabalhos mais recentes, publicados em 2019, que alcançaram a pontuação máxima para esse critério (48 pontos).

- Periódico: primeiramente foram identificados os dez principais periódicos responsáveis por reunir maior quantidade de publicações nacionais e internacionais a respeito do tema. A pontuação ocorreu da seguinte maneira: 40 pontos caso o artigo estivesse inserido no principal periódico, 36 pontos caso estivesse relacionado com o segundo periódico principal, 32, caso estivesse relacionado com o terceiro, e assim sucessivamente até chegar ao décimo periódico que gera uma pontuação de 4 pontos. Para o trabalho que não estava relacionado com nenhum dos dez principais periódicos ou fontes de publicação, não houve contribuição de pontuação nesse critério.

- Afiliação: para que fosse estabelecida a pontuação para esse critério, primeiramente foram identificadas as cinco principais afiliações brasileiras. Caso o trabalho estivesse relacionado com alguma delas, houve contribuição com 20 pontos, caso contrário, não houvepontuar nesse critério.

O score final foi obtido por intermédio da soma de todas essas pontuações. Logo após, os artigos foram classificados em ordem decrescente de seus scores, o que significa que quanto maior fosse esse valor, maior a relevância do artigo. Dessa forma, foi possível realizar uma seleção de maneira a englobar todos os critérios de acordo com as prioridades estabelecidas. Sendo assim, o score final foi obtido de acordo com a Equação 1.

$$
\text { Score }=(N C * 10)+((A P-2003) * 3)+(P P)+(P A)
$$

Persp. Online: exatas \& eng., Campos dos Goytacazes, 27 (10) 54 - 69 - 2020 seer.perspectivasonline.com.br 
Etapa 6 - Revisão Sistemática: após realizada a classificação dos trabalhos brasileiros, foram selecionados alguns trabalhos para que fosse realizada a revisão sistemática destes. $\mathrm{O}$ critério adotado para decidir quais artigos serão utilizados nessa revisão foi o score igual ou superior a 70 pontos, o que resultou na seleção de treze trabalhos dentre os trinta e dois trabalhos brasileiros publicados. A revisão sistemática consiste em uma leitura integral das partes disponíveis de cada trabalho, na tentativa de levantar informações a respeito dos principais aspectos abarcados pelas pesquisas brasileiras relacionadas a essa temática, e realizar um diagnóstico a respeito de como os principais autores brasileiros abordam o papel dos Centros de Inovação (dentre outras organizações orientadas ao mesmo propósito), quanto ao desenvolvimento do empreendedorismo na região onde estão inseridos.

\section{RESULTADOS E DISCUSSÃO}

Por meio da busca inicial na base de dados utilizando-se as palavras-chave e tesauros definidos sem restrições temporais ou quanto ao tipo de trabalho, foram identificados um total de 560 produções científicas que discorrem a respeito da temática abordada. É possível também elaborar um diagrama de Venn que apresenta de forma ilustrativa os resultados para cada busca. O diagrama de Venn encontra-se indicado na Figura 1.

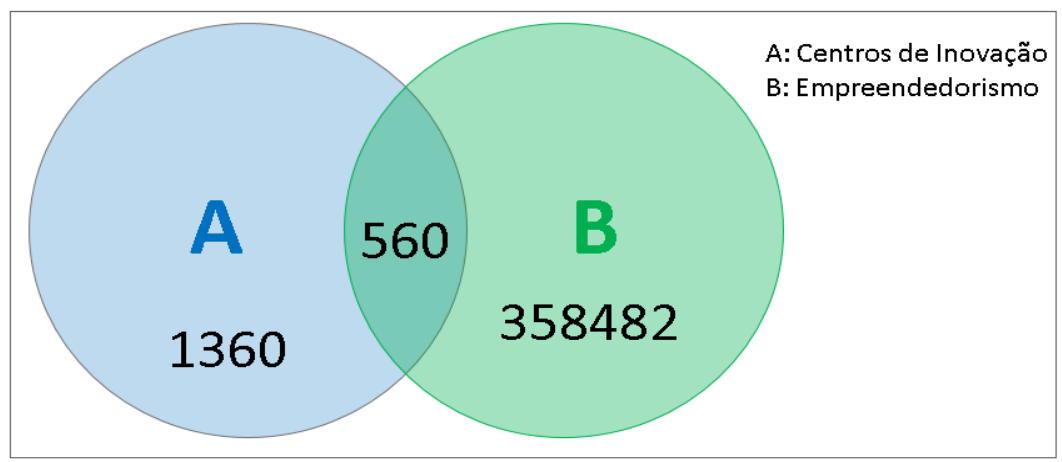

Figura 1: Diagrama de Venn com a quantidade de trabalhos relacionados ao tema encontrados na Scopus, 2019

A quantidade de trabalhos publicados demonstra o quanto o tema "empreendedorismo" é mais antigo e mais trabalhado que o tema "centros de inovação", visto que há uma quantidade demasiadamente maior de trabalhos publicados relacionados ao termo "B" do que ao termo "A". Com relação ao termo B "empreendedorismo", o primeiro trabalho publicado data do ano de 1823, o que demonstra que esse tema já vem sendo trabalhado há muito tempo. Com referência ao termo A "Centros de Inovação", o primeiro trabalho publicado foi em 1971 o que mostra que é um assunto bem mais recente que o empreendedorismo. O primeiro trabalho que aborda as duas temáticas simultaneamente data de 1979, revelando que essa abordagem ocorreu apenas 8 anos após ter sido publicado o primeiro trabalho referente ao empreendedorismo e que o tema Centros de Inovação de fato apresenta uma relação estreita com o tema empreendedorismo.

Analisando-se de forma separada a participação brasileira nas pesquisas, foi elaborado um outro diagrama de Venn, considerando-se somente aqueles trabalhos que para a sua realização estão relacionados com alguma afiliação brasileira. O diagrama de Venn considerando somente os trabalhos brasileiros encontra-se indicado na Figura 2:

Persp. Online: exatas \& eng., Campos dos Goytacazes, 27 (10) 54 - 69 - 2020

seer.perspectivasonline.com.br 


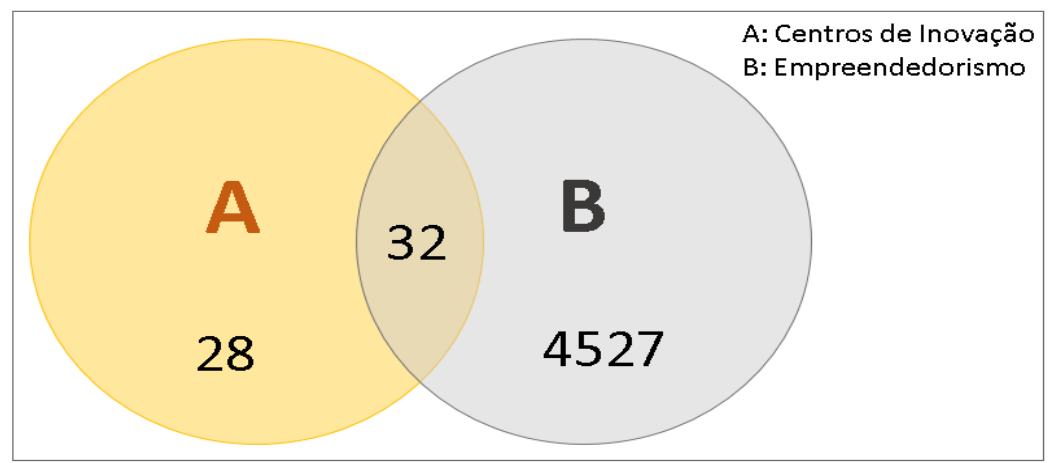

Figura 2: Diagrama de Venn com a quantidade de trabalhos brasileiros encontrados na Scopus

Com base na Figura 2, apesar de o número de trabalhos brasileiros ser bem menor que o total, ainda assim o Brasil responde por uma participação considerável no tocante a essas pesquisas. Foram encontrados 60 trabalhos referentes ao termo A (Centros de Inovação) e 4559 referentes ao termo $\mathrm{B}$ (empreendedorismo). Com relação à interseção $\mathrm{A} / \mathrm{B}$, foram encontrados 32 trabalhos que discorrem simultaneamente sobre Centros de Inovação e empreendedorismo.

O primeiro trabalho brasileiro sobre Centros de Inovação data de 2003, mesmo ano em que ocorreu a primeiro pesquisa brasileira que discorre sobre Centros de Inovação e empreendedorismo, ao passo que no mundo esses tipos de pesquisas começaram a ocorrer respectivamente em 1971 e 1979. Isso evidencia que o Brasil começou a pesquisar sobre o assunto tardiamente, no entanto, sua participação é crescente e vem ganhando espaço. A Figura 3 mostra os principais países relacionados às pesquisas da intersecção $\mathrm{A} / \mathrm{B}$ :

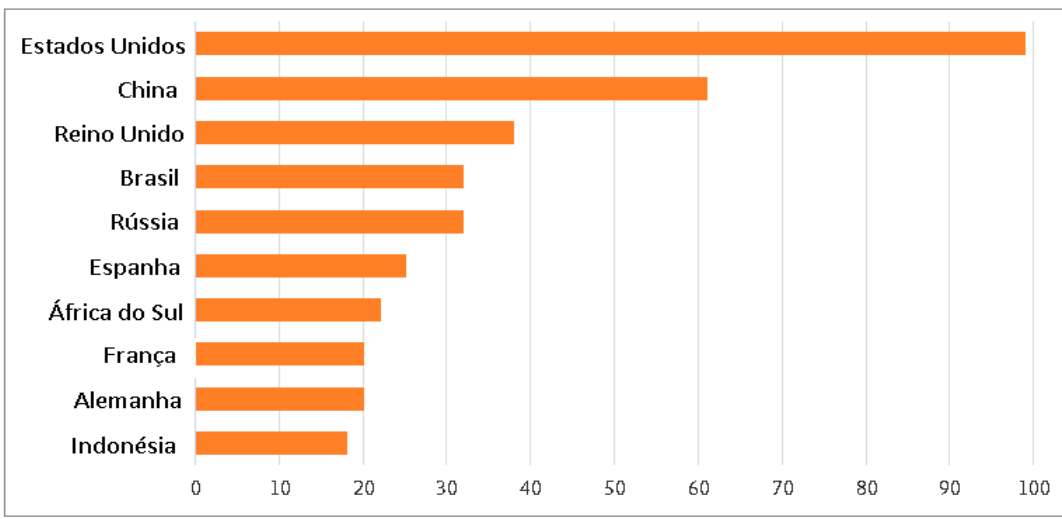

Figura 3: Países mais influentes e seu número de publicações.

De acordo com a Figura 3, o Brasil ocupa o quarto lugar dentre os países que mais realizaram pesquisas a respeito do tema (empatado com a Rússia), contando com 32 trabalhos publicados e ficando atrás somente dos Estados Unidos, China e Reino Unido. Com isso, conclui-se que o Brasil, apesar de ter iniciado essas pesquisas tardiamente, ocupa um lugar de destaque com relação a essa temática.

Vale destacar que se feita uma análise considerando cada termo em separado, o Brasil também ocuparia uma posição de destaque. Com referência ao termo A (Centros de Inovação), ocupa o sexto lugar com 60 trabalhos publicados (atrás de Estados Unidos, China, Reino Unido, Alemanha e Rússia); com relação ao termo B ocupa o $15^{\circ}$ lugar, uma posição

Persp. Online: exatas \& eng., Campos dos Goytacazes, 27 (10) 54 - 69 - 2020

seer.perspectivasonline.com.br 
um pouco pior se comparada ao termo $\mathrm{A}$ e à intersecção $\mathrm{AB}$. Possivelmente se deve ao fato de o Brasil ter demorado a iniciar as pesquisas sobre empreendedorismo, tendo começado essas pesquisas com certo atraso em comparação com outros países; mas de qualquer forma ainda vem conseguindo ocupar uma boa posição.

\subsection{Análise bibliométrica dos resultados}

Para que seja possível selecionar os principais trabalhos brasileiros com base no método estabelecido é necessário primeiramente realizar uma análise bibliométrica. Para tal, foram identificados os dez principais periódicos e as cinco principais afiliações brasileiras relacionadas ao tema. Considerou-se como principais periódicos aqueles que apresentam maior quantidade de publicações levando em conta as publicações nacionais e internacionais.

A Tabela 2 apresenta os dez principais periódicos relacionados ao tema, juntamente com suas respectivas quantidades de publicação.

Tabela 2: Principais periódicos relacionados ao tema

\begin{tabular}{c|c}
\hline Título do Periódico & $\begin{array}{c}\text { Número de } \\
\text { trabalhos }\end{array}$ \\
\hline $\begin{array}{c}\text { International Journal of Entrepreneurship and Innovation } \\
\text { Management }\end{array}$ & 19 \\
\hline $\begin{array}{c}\text { International Journal or Entrepreneurship and Small } \\
\text { Business }\end{array}$ & 14 \\
\hline Technovation & 10 \\
\hline ASEE Annual Conference and Exposition Conference Proceedings & 9 \\
\hline Industry and Higher Education & 9 \\
\hline Actual Problems of Economics & 7 \\
\hline International Journal of Technology Management & 7 \\
\hline Proceedings of the European Conference on Innovation and \\
Entrepreneurship Ecie & 7 \\
\hline Journal of Business Venturing & 6 \\
\hline Economic Development Quarterly & 5 \\
\hline
\end{tabular}

Com relação às afiliações brasileiras relacionadas ao tema, encontram-se indicadas na Figura 4 as cinco principais.

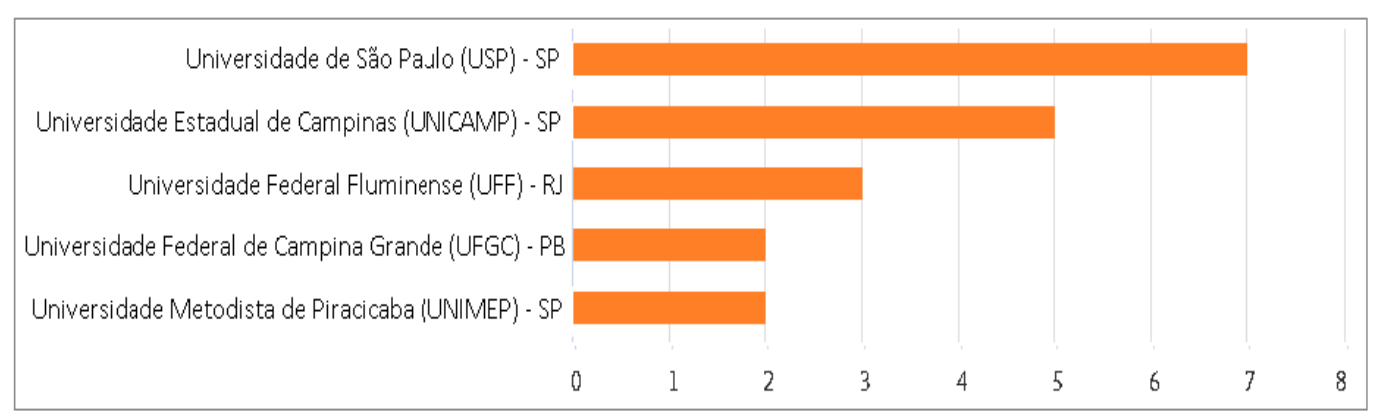

Figura 4: Principais afiliações brasileiras relacionadas ao tema

Persp. Online: exatas \& eng., Campos dos Goytacazes, 27 (10) 54 - 69 - 2020

seer.perspectivasonline.com.br 
Com base na Figura 4, a USP é a principal afiliação brasileira relacionada ao tema, sendo responsável por sete dos trinta e dois trabalhos publicados. Pode-se perceber também a forte influência do estado de São Paulo no tocante a essas pesquisas, visto que três das cinco principais afiliações são desse estado. Dentre as cinco principais afiliações quatro pertencem à região sudeste, visto que além das três afiliações paulistas há a presença também da UFF com dois trabalhos, que pertence ao estado do Rio de Janeiro. Apenas uma afiliação dentre as cinco principais não pertence à região Sudeste, no caso a UFCG da Paraíba, que pertence à região nordeste.

É possível também elaborar um gráfico que representa a evolução cronológica das pesquisas brasileiras relacionadas ao tema. A Figura 5 apresenta um gráfico indicativo da quantidade de trabalhos brasileiros publicados em cada ano.

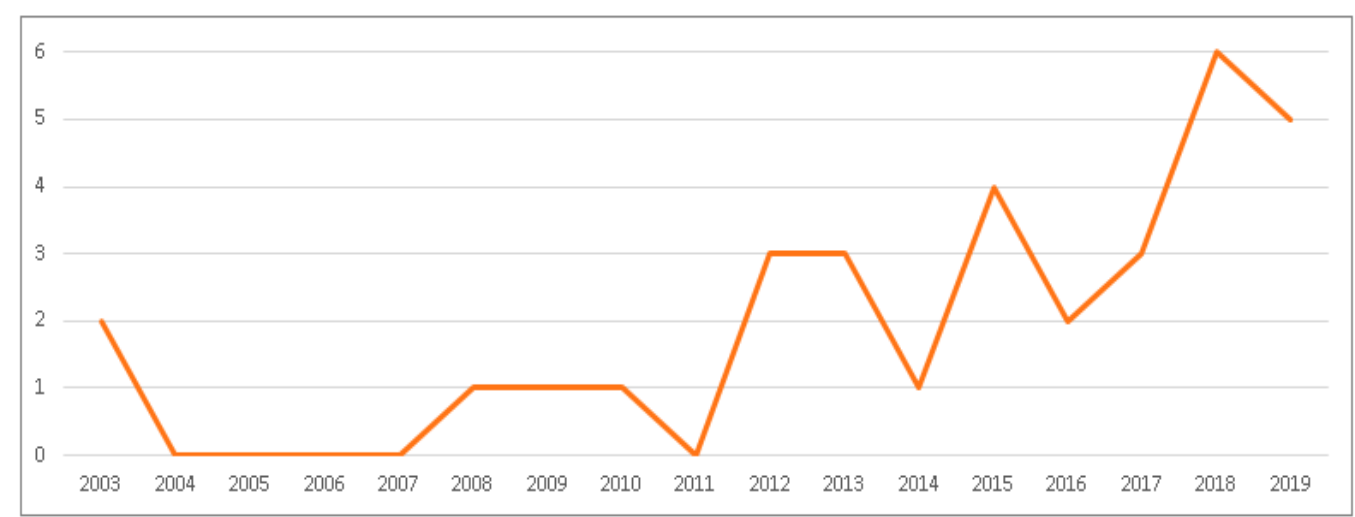

Figura 5: Evolução das pesquisas a respeito do tema realizadas no Brasil

Com base na Figura 5, verifica-se que, apesar de apresentar tendência crescente, o gráfico que retrata o número de trabalhos brasileiros de acordo com o passar dos anos não segue um padrão. O ano de 2003 marca o início das pesquisas sobre o tema no Brasil, e apresenta dois trabalhos publicados. Durante o período de 2004 e 2007 não houve publicações, e entre 2008 e 2011 o número de trabalhos ficou entre 0 e 1 . Todavia, em 2012 pode-se observar um impulso, tendo ocorrido picos nos anos de 2012 e 2013 com três trabalhos publicados. Esse número caiu para um no ano de 2014, no entanto em 2015 voltou a ocorrer um aumento, com quatro trabalhos publicados.Apesar de ter ocorrido uma pequena queda no ano de 2016, que teve duas publicações, pode-se observar que a partir desse ano o número de pesquisas foi aumentando, passando para três em 2017, seis em 2018 (ano de pico) e cinco em 2019. Portanto, pode-se concluir que apesar de apresentar uma distribuição irregular ao longo do período analisado, ainda assim é possível afirmar que a quantidade de pesquisas no Brasil a respeito dessa temática apresenta uma tendência crescente.

Os autor de trabalhos brasileiros com mais trabalhos publicados é Anholon, R., que conta com quatro publicações. Empatados em segundo lugar aparecem Garcia, F. P., Quelhas, O. L. G. e Rampasso, I. S., com dois trabalhos publicados. Os demais autores brasileiros identificados apresentam um trabalho publicado cada.

\subsection{Classificação e seleção dos trabalhos}

Uma vez identificados os principais periódicos e as principais afilações relacionadas ao tema, pode-se utilizar o método definido para poder classificar e selecionar os trabalhos brasileiros a serem analisados na revisão sistemática.

Persp. Online: exatas \& eng., Campos dos Goytacazes, 27 (10) 54 - 69 - 2020

seer.perspectivasonline.com.br 
Foram considerados como trabalhos brasileiros aqueles que possuem vínculo com pelo ou menos uma afiliação brasileira. Os trabalhos foram pontuados de acordo com os critérios estabelecidos e por meio da soma de cada pontuação foram definidos seus scores, conforme indicado na Tabela 3.

Tabela 3: Classificação dos trabalhos com suas respectivas pontuações

\begin{tabular}{|c|c|c|c|c|c|c|c|}
\hline & Título & Autor (es) & $\begin{array}{c}\text { Pontuação } \\
\text { Citação }\end{array}$ & $\begin{array}{c}\text { Pontuação } \\
\text { Ano }\end{array}$ & $\begin{array}{c}\text { Pontuação } \\
\text { Periódico }\end{array}$ & \begin{tabular}{|c} 
Pontuação \\
Afiliação
\end{tabular} & Total \\
\hline $1^{\circ}$ & $\begin{array}{c}\text { Assessment of business incubators green } \\
\text { performance: } A \text { framework and its } \\
\text { application to Brazilian cases }\end{array}$ & $\begin{array}{c}\text { Fonseca e Chiappeta } \\
\text { Jabbour (2012) }\end{array}$ & 200 & 27 & 32 & 0 & 259 \\
\hline $2^{\circ}$ & $\begin{array}{c}\text { Business incubators as a technological } \\
\text { infrastructure for supporting small } \\
\text { innovative firm's activities }\end{array}$ & $\begin{array}{l}\text { Vedovello e Godinho } \\
\qquad(2003)\end{array}$ & 150 & 0 & 40 & 0 & 190 \\
\hline $3^{\circ}$ & $\begin{array}{l}\text { Creating entrepreneurial universities in na } \\
\text { emerging economy: Evidence from Brasil }\end{array}$ & Dalmarco et al. (2018) & 90 & 48 & 0 & 0 & 138 \\
\hline $4^{\circ}$ & $\begin{array}{l}\text { Social innovation in a developing } \\
\text { country: Invention and diffusion of the } \\
\text { Brazilian cooperative incubator }\end{array}$ & Almeida et al. (2012) & 80 & 27 & 0 & 20 & 127 \\
\hline $5^{\circ}$ & $\begin{array}{l}\text { Proposed business model for the } \\
\text { sustainability of technology business } \\
\text { incubators in Brazil and Portugal }\end{array}$ & Lobosco et al. (2019) & 10 & 48 & 40 & 20 & 118 \\
\hline $6^{\circ}$ & $\begin{array}{l}\text { Business incubators in Brazil: Main gaps } \\
\text { to be explored by academic researchers }\end{array}$ & Tietz et al. (2015) & 60 & 36 & 0 & 20 & 116 \\
\hline $7^{\circ}$ & $\begin{array}{l}\text { Business incubators in Brazil: Does } \\
\text { affiliation matter? }\end{array}$ & Chandra et al. (2014) & 40 & 33 & 36 & 0 & 109 \\
\hline $8^{\circ}$ & $\begin{array}{l}\text { Strategic assets in technology-based } \\
\text { incubators in Brazil }\end{array}$ & Fernandes et al. (2017) & 40 & 42 & 0 & 20 & 102 \\
\hline $9^{\circ}$ & $\begin{array}{c}\text { Management through performance } \\
\text { indicators: Results in a technoogical } \\
\text { business incubator }\end{array}$ & Ferreira et al. (2008) & 70 & 15 & 0 & 0 & 85 \\
\hline $10^{\circ}$ & $\begin{array}{l}\text { Universities, local partnerships and the } \\
\text { promotion of youth entrepreneurship }\end{array}$ & Bezerra et al. (2017) & 40 & 42 & 0 & 0 & 82 \\
\hline $11^{\circ}$ & $\begin{array}{l}\text { The process of technology transfer in } \\
\text { Brazilian public universities through } \\
\text { technological innovation centers }\end{array}$ & Silva et al. (2015) & 20 & 36 & 0 & 20 & 76 \\
\hline $12^{\circ}$ & $\begin{array}{l}\text { Analysis of the Brazilian } \\
\text { entrepreneurial ecosystem in the } \\
\text { perception of business incubator } \\
\text { professionals }\end{array}$ & Silva et al. (2018) & 10 & 45 & 0 & 20 & 75 \\
\hline $13^{\circ}$ & $\begin{array}{c}\text { Profiles of entrepreneurship and } \\
\text { innovation: Debate on business } \\
\text { incubators in Brazil }\end{array}$ & Dorion et al. (2010) & 30 & 21 & 0 & 20 & 71 \\
\hline $14^{\circ}$ & $\begin{array}{c}\text { Science, technology and innovation in } \\
\text { the Brazilian State of São Paulo: The } \\
\text { need for public policies for region- } \\
\text { based development }\end{array}$ & Torres et al. (2013) & 10 & 30 & 0 & 20 & 60 \\
\hline $15^{\circ}$ & $\begin{array}{c}\text { Application of strategic planning } \\
\text { methodology in seven Brazilian } \\
\text { preincubated enterprises in a } \\
\text { Technological Innovation Center (TIC) }\end{array}$ & Machado et al. (2017) & 10 & 42 & 0 & 0 & 52 \\
\hline $16^{\circ}$ & $\begin{array}{c}\text { Overview of opportunities for graduates } \\
\text { of higher education in Brazil: The role of } \\
\text { innovation in the creation of new job } \\
\text { markets }\end{array}$ & Pereira et al. (2016) & 10 & 39 & 0 & 0 & 49 \\
\hline $17^{\circ}$ & $\begin{array}{c}\text { Proposal of an innovative methodology } \\
\text { using the cognitive mapping and the } \\
\text { balanced scorecard: A case study at a } \\
\text { micro-enterprise. }\end{array}$ & Pessoa (2015) & 10 & 36 & 0 & 0 & 46 \\
\hline
\end{tabular}

Dentre os trinta e dois trabalhos brasileiros encontrados, quinze deles não obtiveram nenhuma citação, e por isso foram eliminados. Os outros dezessete trabalhos restantes que obtiveram uma ou mais citações tiveram seus scores calculados a partir de pontos distribuídos nas modalidades: citação, ano, periódico e afiliação, de acordo com os critérios apresentados 
na metodologia. Ao final, foram selecionados para revisão sistemática todos aqueles trabalhos cujo score final tenha sido igual ou superior a 70 pontos. Na Tabela 3 seguem indicados os trabalhos e suas respectivas pontuações em cada quesito; os que aparecem grifados em azul foram selecionados para a revisão sistemática; os demais que aparecem grifados em vermelho não foram utilizados na revisão.

Por meio da Tabela 3 verificou-se que, com base nos critérios de pontuação estabelecidos, foram selecionados para revisão sistemática um total de treze dos dezessete trabalhos brasileiros que apresentam pelo ou menos uma citação. Sendo assim, é necessário analisar quais aspectos são abordados por esses trabalhos e quais são suas principais contribuções para as pesquisas nessa área.

\subsection{Revisão sistemática}

O trabalho de Fonseca e Chiappeta Jabbour (2012) foi o trabalho brasileiro que obteve maior score com base nos critérios, o que significa que pode ser considerado como o mais relevante até o momento. Neste trabalho, os autores buscam avaliar o desempenho ecológico de incubadoras de empresas. Para tal, foi realizada uma revisão de literatura sobre gestão verde e políticas ecológicas em empreendimentos de pequeno porte, tendo sido identificadas variáveis relevantes para se elaborar uma estrutura capaz de avaliar e classificar o desempenho ecológico de incubadoras, com base em níveis de maturidade ambiental. Sendo assim, propõem uma discussão em relação ao papel das incubadoras ao estimularem o desenvolvimento de novos negócios de uma maneira sustentável.

Vedovello e Godinho (2003) discorreram a respeito do papel das incubadoras como infraestrutura tecnológica para apoiar pequenas empresas inovadoras. As incubadoras podem agir como um instrumento intermediário entre a nova empresa e as infraestruturas tecnológicas, ao abrigar novos negócios e apoiar seus inquilinos por meio de serviços técnicos diretos, tais como gestão, contabilidade, dentre outros serviços empresariais e serviços indiretos, tais como agentes de ligação intermediários, atuando no tocante à intermediação com fornecedores de insumos específicos. Entre as infraestruturas fornecidas pelas incubadoras pode-se citar o capital humano (como por exemplo a educação, treinamento e experiência), capital físico (instrumentação e sistemas de patente), e recursos tecnológicos. As incubadoras podem atuar como provedoras de capital para as atividades das pequenas e médias empresas (PMEs), fornecedoras de equipamentos, e indicadora de clientes e fornecedores.

No trabalho de Dalmarco et al. (2018) realizaram um estudo de caso no tocante da criação de incubadoras em economias emergentes, e utilizam para tal, o exemplo do Brasil. De acordo com os autores, ocorreram ao todo três ondas de empreendedorismo: a primeira ocorreu em universidades pioneiras nos EUA, definindo uma política de patentes baseada na parceria universidade/indústria; a segunda onda ocorreu na Europa Ocidental; e a terceira onda, na qual se inclui o Brasil, possui o empreendedorismo acadêmico como uma de suas principais pautas. Sendo assim, o objetivo do trabalho foi identificar atividades e políticas efetivas que pudessem incentivar a transferência de tecnologia acadêmica no Brasil. Por meio de um estudo de caso exploratório, foram realizadas dezoito entrevistas com empresários incubados e gerentes de incubadoras de empresas universitárias no sul do Brasil. A principal descoberta é que a maioria das startups acadêmicas se baseia nas próprias tecnologias do empreendedor, e não nas patentes da universidade. Os autores também atestam sobre a importância de um treinamento empresarial e dos novos empreendimentos para o desenvolvimento socioeconômico.

Persp. Online: exatas \& eng., Campos dos Goytacazes, 27 (10) 54 - 69 - 2020

seer.perspectivasonline.com.br 
Almeida et al. (2012) discorreram a respeito da invenção e difusão da incubadora cooperativa brasileira, que representa uma readaptação criativa de um modelo de incubadora elaborado a partir de pesquisas acadêmicas e importado dos EUA. A incubadora social aborda questões relacionadas à exclusão social pobreza e desemprego, com o objetivo de estimular os moradores das favelas a criarem seus próprios empregos, permitindo assim abordar a questão do crescimento em empresas sociais. O trabalho emprega um modelo tripla hélice (empresa, governo e universidade) para descrever a difusão deste tipo de incubadora no empreendedorismo social.

Lobosco et al. (2019) propuseram um modelo de negócios para ampliar a sustentabilidade de incubadoras de tecnologia no Brasil e em Portugal. O estudo buscou mapear os recursos que afetam os custos e geram receitas, estudar a natureza das parcerias estratégicas, analisando proposições de valor e propor um modelo de negócios para a sustentabilidade de incubadoras. O modelo, que inclui boas práticas para incubação de empresas, foi aplicado a dez incubadoras, sendo seis brasileiras e quatro portuguesas. Foi comprovada a eficiência do modelo para ajudar as incubadoras a alcançar sustentabilidade por intermédio de uma maior eficiência organizacional.

Tietz et al. (2015) discorreram a respeito das principais lacunas sobre incubadoras no Brasil a serem exploradas por pesquisadores. Os autores afirmam a importância dessa instituição em relação a redução do o índice de mortalidade de empresas iniciantes e melhorar o desempenho da economia do país. Sendo assim, realizam uma revisão sistemática, orientada a identificar os principais temas de pesquisa que vem sendo realizadas sobre incubadoras brasileiras. Constatou-se que a maioria das pesquisas referem-se à prestações dos serviços oferecidos pelas incubadoras e seu gerenciamento, mas ainda existem lacunas importantes que devem ser exploradas. Portanto, os autores atestam sobre a urgência de pesquisas com relação a alguns assuntos relevantes: trípla hélice (que é extremamente importante para o sucesso dos programas de incubação), inter-relação entre incubadoras, foco estratégico adotado pelas incubaddoras e tipos de negócio incubados.

Chandra et al. (2014) exploraram as diferenças entre incubadoras de empresas universitárias e não universitárias com o objetivo de avaliar o impacto da afiliação quanto ao desempenho da incubadora e sua capacidade de conseguir financiamento e vínculos formais diretos com parceiros externos. Foi utilizada uma amostra empírica de quarenta e nove incubadoras do estado de São Paulo e os resultados indicam que, de fato, as incubadoras afiliadas às universidades conseguiram obter níveis mais altos de financiamento de diversas fontes, em comparação às incubadoras não afiliadas às universidades.

Fernandes et al. (2017) analisaram a respeito dos ativos tecnológicos em incubadoras brasileiras, na tentativa de identificar quais deles mais contribuíram para o lançamento de novos produtos. Para tal, foram aplicados questionários para gerentes de incubadoras e proprietários de empresas incubadas do estado de São Paulo. Os ativos analisados foram: ativos de conhecimento científico (adquiridos por meio de parcerias com universidades e centros de pesquisa) e recursos financeiros (obtidos por meio de relacionamento com agências de fomento), ambos ativos intangíveis, escolhidos por serem de difícil imitação pelos concorrentes. Foram utilizadas como técnicas estatísticas a análise de correlação e a regressão linear múltipla para avaliar as respostas. Concluiu-se que os ativos de relacionamento e conhecimento são muito relevantes para o sucesso da incubação; o primeiro auxilia a obtenção de parcerias com universidades e centros de pesquisa; o segundo incentiva a criação de redes que compartilham tecnologia entre empresas incubadas e empresas localizadas em parques científicos que também envolvem outras partes interessadas.

Persp. Online: exatas \& eng., Campos dos Goytacazes, 27 (10) 54 - 69 - 2020

seer.perspectivasonline.com.br 
Ferreira et al. (2007) abordaram em seu trabalho a importância da gestão por indicadores de desempenho para uma incubadora empresarial tecnológica. Segundo o autor, existe uma alta taxa de mortalidade e insucesso de novas micro e pequenas empresas o que indica a necessidade de suporte acentuado na gestão dessas empresas. Sendo assim, as incubadoras surgem como importantes opções para fornecer esse apoio e suporte, entretanto, muitas ainda não dispõem de mecanismos fortes de sustentação empresarial. Em geral, novos empreendimentos oferecem grandes riscos, principalmente no que concerne às altas taxas de juros e baixas aplicações de capital de risco. Sendo assim, o papel da incubadora deve focar no processo de negócios das novas empresas, dando visibilidade à evolução do negócio, apoiando o fortalecimento da produtividade e o aumento da competitividade no mercado, para tal, cita os indicadores de desempenho como importantes ferramentas.

Bezerra et al. (2017) discorreram a respeito do empreendedorismo juvenil no ambiente universitário, atestando que há poucas pesquisas relacionadas a esse assunto. Os autores realizam um estudo de caso na tentativa de compreender como as universidades reúnem parceiros locais em apoio a jovens empreendedores e oferece compreensões a respeito de estratégias que podem ser implementadas no tocante a apoiar o empreendedorismo jovem. Os autores atestam que os jovens recém-formados são mais propensos a criar empresas do que seus professores e destacam a importância das universidades como relevante instrumento de suporte para esses empreendimentos. Dada a relevância dessa temática, os autores contribuem com as pesquisas na área por meio da investigação do empreendedorismo juvenil no contexto das universidades (área pouco pesquisada) e de insights para formuladores de políticas e gestores universitários para melhorar as ações destinadas à promoção do empreendedorismo jovem.

Silva et al. (2015) analisaram o processo de transferência de tecnologia em universidades públicas brasileiras por intermédio de núcleos de inovação tecnológica, no estado do Paraná. O estudo foi realizado tendo como objeto um Centro de Inovação e possibilitou identificar seus pontos fortes (equipe profissional com excelente nível de formação) e pontos fracos (dificuldades de estabelecer relações internas entre os membros da equipe). Verificou-se que o Centro também enfrenta dificuldades para desenvolver contatos externos, como por exemplo com o Governo, Universidades e outras instituições.

Silva et al. (2018) analisaram o nível de maturidade do ecossistema empreendedor brasileiro de acordo com as opiniões percepções de profissionais de incubadoras de empresas. Para tal, foi realizada uma pesquisa com setenta e quatro profissionais que publicaram pelo menos um trabalho relacionado a esse tema no Brasil. A maturidade foi avaliada com base em um modelo composto por seis variáveis: apoio, governo, finanças, capital humano, cultura e mercado. Os dados foram validados estatisticamente mediante de equações estruturais. Por meio da validação, foi possível analisar o nível de maturidade atribuído a cada variável e concluiu-se que o ecossistema brasileiro apresenta nível intermediário de maturidade, sendo necessário realizar algumas melhorias.

Dorion et al. (2010) investigaram o perfil de empreendedorismo e inovação no Brasil, por meio de um debate sobre incubadoras. Foram estudados os perfis dos atores e das empresas que integram cinco das principais incubadoras brasileiras do estado do Rio Grande do Sul. O estudo permite identificar aspectos convergentes e divergentes com relação às incubadoras e empresas incubadas, além de fornecer um panorama a respeito do perfil dos atores desse ambiente com relação ao empreendedorismo e inovação.

Persp. Online: exatas \& eng., Campos dos Goytacazes, 27 (10) 54 - 69 - 2020

seer.perspectivasonline.com.br 


\section{CONCLUSÃO}

Com base em tudo o que foi realizado e discutido no decorrer deste trabalho pode-se inferir a respeito da importância dos ambientes orientados à inovação no tocante ao desenvolvimento do empreendedorismo e inovação; e também da importância das análises bibliométricas e das revisões sistemáticas para facilitar o estudo e compreensão a respeito do tema.

Por meio da análise bibliométrica concluiu-se que o Brasil iniciou tardiamente as pesquisas com relação ao tema, se comparado aos outros países. No entanto, ainda assim apresenta uma posição de destaque, ocupando o quarto lugar entre os países com maior quantidade de publicação sobre o assunto. As principais afiliações brasileiras se concentram na região sudeste, em especial no estado de São Paulo, e o tema apresenta tendência crescente com relação ao número de publicações no Brasil, pois embora existam algumas irregularidades com relação à distribuição do número de trabalhos por ano no Brasil, pode-se observar uma propensão de aumento na quantidade de pesquisas nos últimos anos.

Com base na revisão sistemática, concluiu-se que os principais trabalhos brasileiros a respeito do tema abordam questões tais como: a contribuição das incubadoras com infraestrutura tecnológica para apoio a startups, utilização de indicadores de desempenho para avaliar a gestão das incubadoras, o papel das incubadoras como centros de transferência de tecnologia e fatores relevantes para seu sucesso, análise do nível de maturidade do ecossistema empreendedor, investigações a respeito do perfil de empreendedorismo e inovação no Brasil, principais lacunas que podem ser abordadas por novas pesquisas e comparações entre incubadoras universitárias e não universitárias, o que permitiu constatar que as incubadoras afiliadas às universidades conseguem obter maior visibilidade e facilidades com relação à captação de investimentos e recursos. Vale destacar também que os trabalhos brasileiros também apresentam foco com relação à sustentabilidade e desempenho ecológico das incubadoras, na tentativa de avaliar o quanto elas vêm apoiando o desenvolvimento de empreendedorismo e inovação orientados ao desenvolvimento sustentável.

\section{REFERÊNCIAS}

ALMEIDA, M.; MELLO, J. M. C.; ETZKOWITZ, H. Social innovation in a developing country: invention and diffusion of the Brazilian cooperative incubator.International Journal of Technology and Globalisation, v. 6, n. 3, p. 206-224, 2012.

BEZERRA, E. D.; BORGES, C.; ANDREASSI, T. Universities, local partnerships and the promotion of youth entrepreneurship. International Review of Education, v. 63, n. 5, p. 703-724, 2017. DOI: 10.1007/s11159-017-9665-y

CHANDRA, A.; CHAO, C.-A.; ASTOLPHO, E. C. Business incubators in Brazil: does affiliation matter? International Journal of Entrepreneurship and Small Business, v. 23, n. 4, p. 436-455, 2014. DOI: 10.1504/IJESB.2014.065678

DALMARCO, G.; HULSINK, W.; BLOIS, G. V. Creating entrepreneurial universities in an emerging economy: Evidence from Brazil. Technological Forecasting and Social Change, v. 135, p. 99-111, 2018. DOI: 10.1016/j.techfore.2018.04.015

Persp. Online: exatas \& eng., Campos dos Goytacazes, 27 (10) 54 - 69 - 2020

seer.perspectivasonline.com.br 
DIAMANTOPOULOU, V.; ANDROUTSOPOULOU, A.; CHARALABIDIS, Y. Towards a taxonomy of services offered by start-up business incubators: insights from the Mediterranean region. International Journal of Entrepreneurship and Small Business, v. 33, n. 4, p. 494$513,2018$.

DORION, E.; CHALELA, L. R.; LAZZARI, F.; SEVERO, E. A.; GIULIANI, A. C. Profiles of entrepreneurship and innovation: debate on business incubators in Brazil. World Review of Entrepreneurship, Management and Sustainable Development, v. 6, n. 1-2, p. 17-34, 2010. DOI: 10.1504/WREMSD.2010.031636

FERNANDES, C. ; OLIVEIRA JR, M.; SBRAGIA， R.; BORINI， F. Strategic assets in technology-based incubators in Brazil. European Journal of Innovation Management, v. 20, n. 1, pp. 153-170, 2017. DOI: 10.1108/EJIM-04-2016-0043.

FERREIRA, M.P.; DE ABREU, A.F.; DE ABREU, P.F.; APOLINÁRIO, L.G.; DA CUNHA, A. d'A. Management through performance indicators: Result in a tecnhological business incubator. Production. v. 18 , n. 2, pp. 302-318, 2007. DOI: 10.1590/S010365132008000200008.

FONSECA, S. A.; JABBOUR, C. Jose C. Assessment of business incubators' green performance: A framework and its application to Brazilian cases. Technovation, v. 32, n. 2, p. 122-132, 2012. DOI: 10.1016/j.technovation.2011.10.006.

GUY, I. A look at Aston science park. Technovation, v. 5, n. 16, p. 217-218, 1996.

LINK, A. N.; YANG, U. Yeong. On the growth of Korean technoparks. International Entrepreneurship and Management Journal, v. 14, n. 2, p. 405-410, 2018. DOI: 10.1007/s11365-017-0459-2.

LOBOSCO, A.; MACCARI, E. A.; COSTA, P. R. D.; ALMEIDA, M. I. R. D. Proposed business model for the sustainability of technology business incubators in Brazil and Portugal. International Journal of Entrepreneurship and Innovation Management, v. 23, n. 2, p. 97-141, 2019. DOI: 10.1504/IJEIM.2019.098141.

LUZ, A. A.; KOVALESKI, J. L.; REIS, D. R.; ANDRADE JÚNIOR, P. P.; ZAMMAR, A. Análise de empresa incubada como habitat de empreendedorismo, inovação e competitividade. Revista Gestão da Produção Operações e Sistemas, n. 4, p. 43-56, 2012. DOI: $10.15675 /$ gepros.v0i4.584

MACHADO, A. de B.; SILVA, A. R. L.; CATAPAN, A. H. Bibliometria sobre concepção de ambientes de inovação. Revista Navus, Florianóplis/SC, v.6, n.3, p. 88-96, 2016.

REDONDO, M.; LEON, L.; POVEDANO, F.J.; ABASOLO, L.; PEREZ-NIETO, M.A.; LOPEZ-MUÑOZ, F. A bibliometric study of the scientific publications on patient-reported outcomes in rheumatology. Seminars in Arthritis and Rheumatism, v. 46, n. 6, p. 828-833, 2017. DOI: $10.1016 /$ j.semarthrit.2016.12.002

SILVA, L.C.S.; KOVALESKI, J.L.; GAIA, S.; SEGUNDO, G.S.A.; TEN CATEN, C.S. The process if technology transfer in Brazilian public universities through technological innovation centers. Interciencia, v. 40, n.10, p. 664-669, 2015.

Persp. Online: exatas \& eng., Campos dos Goytacazes, 27 (10) 54 - 69 - 2020 seer.perspectivasonline.com.br 
SILVA, M.C.; ANHOLON, R.; RAMPASSO, I.S.; FILHO, W.L.; SILVA, D. Analysis of the Brazilian entrepreneurial ecosystem in the perception of business incubator professionals. International. Journal of Business Innovation and Research v. 16, n. 4, p. 507-530, 2018. DOI: doi.org/10.1504/IJBIR.2018.093524

TIETZ, G.; ANHOLON, R.; ORDOÑEZ, R. E. C.; QUELHAS, O. L. Business incubators in Brazil: Main gaps to be explored by academic researches. Journal of Technology Management and Innovation. v. 10, n. 4, p. 18-27, 2015. DOI: 10.4067/S071827242015000400003

UNESCO. Concept and definition | United Nations Educational, Scientific and Cultural Organization. Disponível em: <http://www.unesco.org/new/en/natural-sciences/sciencetechnology/university-industry-partnerships/science-and-technology-parkgovernance/concept-and-definition/>. Acesso em: 8 ago. 2018.

VEDOVELLO, C.; GODINHO, M. Business incubators as a technological infrastructure for supporting small innovative firms' activities. International Journal of Entrepreneurship and Innovation Management. v. 3, n. 1/2, p. 4-21, 2003. DOI: 10.1504/IJEIM.2003.002215. 